\title{
Electrochemical Activation of Aluminum by the Addition of Tin, in 3\% NaCl
}

\author{
Youssef Gouale, ${ }^{*}$ Salma Khatbi and Mohamed Essahli
}

Laboratory of Applied Chemistry and Environment,

Faculty of Science and Technology, Univ. Hassan 1, P.O. Box 5777, Settat, Morocco

Received January 14, 2017; accepted September 15, 2018

\begin{abstract}
The aim of our studies was to show the effect of the addition of tin to aluminum in a solution of sodium chloride $(\mathrm{NaCl} 3 \%)$, by weight, as well as the influence of the alloy immersion time on its corrosion resistance. To do this, we have used, as electrochemical techniques, potentiodynamic polarization and electrochemical impedance spectroscopy and, as metallurgical techniques, hardness parameters and optical microscopy performed on the alloys made of pure aluminum (99.99\%) and pure tin $(99.99 \%)$. The obtained results show that the addition of tin enhances aluminum electrochemical activation, as well as the spontaneous formation of an oxide layer containing $\mathrm{Al}_{2} \mathrm{O}_{3}$, which then protects the metal from further corrosion. During all that process, the alloy immersion in $3 \% \mathrm{NaCl}$ acts by promoting tin's attack and the alloy's corrosion.
\end{abstract}

Keywords: corrosion, activation, aluminum, tin, $\mathrm{NaCl}$, alloy.

\section{Introduction}

Aluminum alloys are used in many sectors, such as automobile and aerospace industries and, very recently, in the field of energy storage batteries, as well as in various aggressive environments, due to its excellent resistance to corrosion [1].

The polarization of high-purity aluminum, in the cathodic sense, in neutral electrolytes, is characterized by the increase in the hydrogen evolution rate beyond a certain limit of the negative potential, as well as by the increase in the metal's dissolution rate. In this case, a number of phenomena could be expected to appear, including hybride's training [2-4].

Aluminum alloys' high corrosion resistance is due to the capacity of their surface to become very passive; this is linked to a quick aluminum reaction with oxygen, which allows creating a thin and amorphous oxide layer [5-8].

Thanks to this oxide layer formed onto the surface, the aluminum alloys are more resistant to corrosion. However, in corrosive environments, aluminum alloys, in contact with the atmosphere, are subject to pitting corrosion, stress corrosion cracking, corrosion fatigue and general attack corrosion. Aluminum is very

\footnotetext{
*Corresponding author. E-mail address: gouale.youssef@gmail.com
} 
resistant to rural atmospheres and marine areas and, conveniently, to the industrial atmosphere, depending on the pollutants proportions. Aluminum is protected by zinc and magnesium, but it is corroded by lead and tin. In these last cases, there must be provision for specific protections to avoid the phenomenon of galvanic corrosion. [9-15]

The objective of our work was to develop alloys based on aluminum, which can very well be used as anodes with a better electrochemical activation, for the cathodic protection of materials, while having a better hardness and resistance to mechanical shock.

\section{Experimental procedure \\ Elaboration of alloys}

The alloys were melted at $70{ }^{\circ} \mathrm{C}$ in a crucible. The choice of a good melting crucible is not always simple, given the wide range of materials, forms and capabilities. When it comes to choosing a crucible that will allow a good homogeneity of our elements, and that will have a good resistance to high temperatures, it is important to consider how and for how long it will be used. For our study, we have chosen one with $4 \mathrm{~cm}$ in diameter. After fusion and cooling until the total solidification was achieved, the ensemble (alloy-crucible) was soaked in water.

We used an electrode made of an Al-Sn alloy, with different contents of tin (2\%, $4 \%$ and $6 \%$ ), in the form of a disk of $1 \mathrm{~cm}^{2}$. In order to obtain reliable and reproducible results, the working electrode underwent, before each test, polishing with different abrasive papers of 400, 600 and 1200 grit size. Then, it was rinsed with distilled water and dried.

The alloys were prepared from metals of $99.5 \%$ purity. The contents of Sn and the melting temperature were chosen in accordance with the phase diagram of the binary Al-Sn system represented in Fig. 1.The binary system of Al-Sn presented an eutectic bearing at $228.3{ }^{\circ} \mathrm{C}$. The composition of the eutectic liquid was approximately $0.5 \%$ by weight of tin.

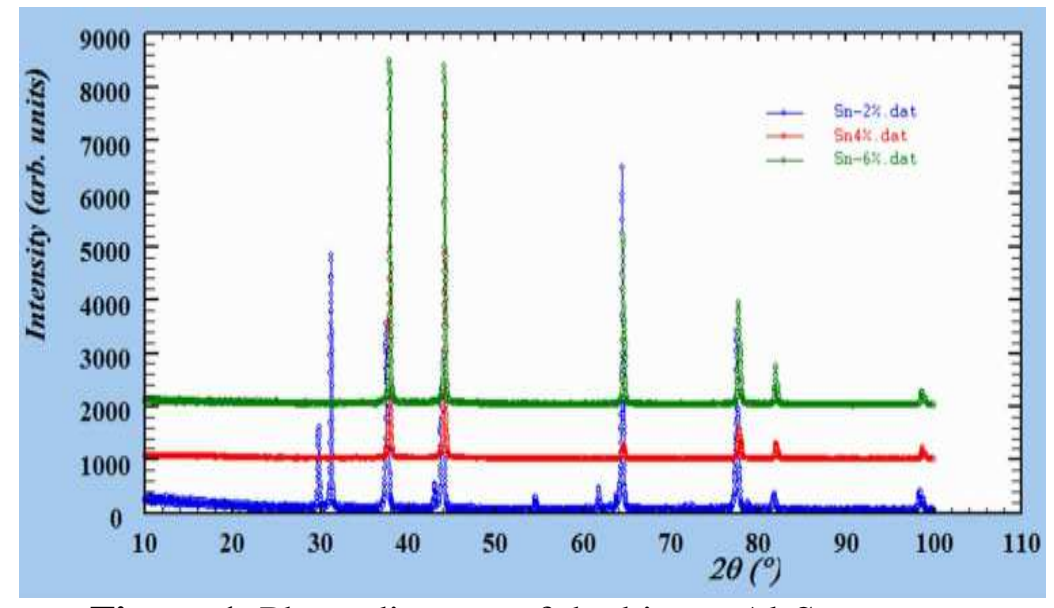

Figure 1. Phase diagram of the binary Al-Sn system.

Before elaborating the Al-Sn alloys, we have analyzed the chemical composition 
of pure Al. After the elaboration of the alloys, we also have analyzed them, to know the exact chemical composition of each element, including the impurities. For this, we have used the "The Thermo Scientific Niton XL5", which is a spectrometer of X-ray fluorescence. It is the newest and faster analyzer in the market nowadays, and it gives fast and accurate results. The chemical composition of the prepared alloys is represented in Table 1. It is a punctual analysis; therefore, the measurements were made at one point of each alloy.

Table 1. Chemical composition of $\mathrm{Al}$ and $\mathrm{Al}-\mathrm{Sn}$ alloys.

\begin{tabular}{cccccccccccc}
\hline $\begin{array}{c}\text { Added Sn } \\
(\boldsymbol{\%})\end{array}$ & $\begin{array}{c}\mathbf{A l} \\
(\boldsymbol{\%})\end{array}$ & $\begin{array}{c}\text { Sn } \\
(\boldsymbol{\%})\end{array}$ & $\begin{array}{c}\mathbf{C r} \\
(\boldsymbol{\%})\end{array}$ & $\begin{array}{c}\mathbf{P} \\
(\boldsymbol{\%})\end{array}$ & $\begin{array}{c}\mathbf{T i} \\
(\boldsymbol{\%})\end{array}$ & $\begin{array}{c}\mathbf{S i} \\
(\boldsymbol{\%})\end{array}$ & $\begin{array}{c}\mathbf{C u} \\
(\boldsymbol{\%})\end{array}$ & $\begin{array}{c}\mathbf{P b} \\
(\boldsymbol{\%})\end{array}$ & $\begin{array}{c}\mathbf{M n} \\
(\boldsymbol{\%})\end{array}$ & $\begin{array}{c}\mathbf{M g} \\
(\boldsymbol{\%})\end{array}$ & $\begin{array}{c}\mathbf{Z n} \\
(\boldsymbol{\%})\end{array}$ \\
\hline $\mathbf{0}$ & 99.50 & ----- & 0.05 & ----- & ---- & 0.28 & 0.05 & ----- & 0.03 & 0.02 & 0.07 \\
\hline $\mathbf{2}$ & 97.91 & 2.00 & 0.001 & 0.01 & ---- & 0.07 & 0.00 & ---- & ---- & ----- & ----- \\
\hline $\mathbf{4}$ & 95.92 & 4.01 & ---- & ---- & 0.02 & ----- & ---- & 0.01 & ----- & 0.02 & ----- \\
\hline $\mathbf{6}$ & 93.86 & 6.00 & 0.014 & 0.03 & 0.00 & 0.00 & ---- & ---- & 0.07 & ----- & 0.01 \\
\hline
\end{tabular}

\section{Preparation of the $\mathrm{NaCl}$ solution}

The solutions were prepared by dissolution of $\mathrm{NaCl}$ in distilled water. The test solutions were freshly prepared before each experiment. For each analysis, the experiment was made thrice to ensure the reproducibility of the results.

\section{$X$-ray diffraction}

The X-ray spectra of the three samples was obtained at room temperature, using a D2 PHASER Bragg-Brentano geometry diffractometer, with $\mathrm{Cu} \mathrm{Ka}=1.5406 \AA$ $(40 \mathrm{kV}, 40 \mathrm{~mA})$ type of radiation, and the $2 \theta$ scanning range was from 15 to 100 ${ }^{\circ}$, with a step of $0.01(2 \theta)$.

\section{Hardness}

The hardness tests were carried out by the Vickers method, using a Testwell durometer under a load of $2 \mathrm{Kg}$. Each measurement corresponds to the average of a maximum of four imprints located on a planar section equivalent to a diameter plan, or perpendicular to the axis of the cylindrical sample. The sections were obtained by sawing, mechanical abrasion and then chemical polishing. Recall that the empirical relationship $\mathrm{HV}=0.3 \mathrm{R}(\mathrm{MPa})$ can be used to assess the maximum load $(\mathrm{R})$ of these alloys.

\section{Optical microscopy}

The physical properties of the quenched solid solutions of aluminum alloys evolved at room temperature. The hardening mechanisms were continuous/discontinuous transformations. This temperature corresponds to 0.5 $\mathrm{TF}$ (melting temperature of the alloy). We know that from 0.4 up to $0.5 \mathrm{TF}$, the elements of the alloy can diffuse. In the case where the kinetics of the discontinuous transformation was rapid at room temperature, we have used the original technique developed by Hilger [16].

\section{Electrochemical techniques}

The electrochemical measurements have been carried out in a cell of 3 electrodes consisting of a saturated calomel reference electrode, a platinum auxiliary 
electrode and an Al-Sn working electrode. Before each test, the alloy was left under an open current for 5 min to achieve a stable state. For this study, we have used 2 types of electrochemical techniques: potentiodynamic polarization and electrochemical impedance spectroscopy (EIS). The potentiodynamic polarization was made by sweeping the potential at a speed of $5 \mathrm{mV} / \mathrm{s}$, from - 1500 to $0 \mathrm{mV}$. We have obtained different kinetic parameters such as corrosion current density $\left(\mathrm{I}_{\mathrm{corr}}\right)$, corrosion potential $\left(\mathrm{E}_{\mathrm{corr}}\right)$ and Tafel slopes (anodic $\beta_{\mathrm{a}}$ ) and cathodic $\left(\beta_{\mathrm{c}}\right)$. The corrosion current density has been measured by extrapolation of Tafel straight lines. The measurements of the electrochemical impedance spectroscopy were performed using a margin of frequency ranging from $30 \mathrm{MHz}$ to $50 \mathrm{kHz}$ at the corrosion potential. For the analysis, we have used a 10 VoltaLab model (PGZ100) device connected to a HP computer with VoltaMaster 4 and OriginLab software for the data acquisition.

\section{Results and discussion $X$-ray diffraction}

The X-ray diffraction shows that precipitates are of Al type (represented in Fig. 2). Furthermore, Sn element did not participate to the mechanisms of structural hardening of Al-Sn alloys. The influence of tin was reflected by an increase in hardness.

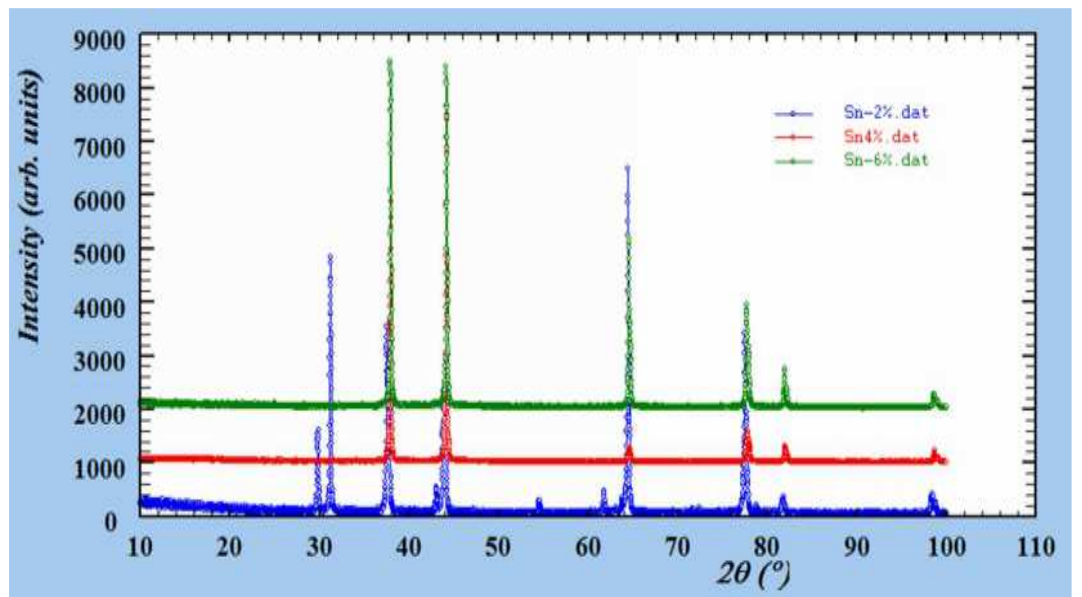

Figure 2. X-ray diffraction spectra of the cast alloys: Al-2\%Sn, Al-4\%Sn and Al-6\%Sn, at $20^{\circ} \mathrm{C}$.

\section{Hardness}

Fig. 3 shows the hardness evolution in function of time. At $20^{\circ} \mathrm{C}$, the $\mathrm{Al}-2 \% \mathrm{Sn}$ oversaturated hardened cast alloy had a hardness of $11.15 \mathrm{HV}$, which is almost the double of that of pure aluminum. This shows that the alloy was already partially transformed during cooling. At room temperature, the maximum hardness was reached at the end of one day $(11.45 \mathrm{HV})$, and then the hardness slightly decreased and stabilized, to achieve $11.29 \mathrm{HV}$ at the end of 5 days. For the Al-6\%Sn alloy, the figure shows an increase in the hardness as a function of time, compared to the first sample gross casting, at room temperature. At room temperature, the maximum hardness was reached at the end of one day (11.55 
$\mathrm{HV}$ ); then, it slightly decreased, to achieve $11.25 \mathrm{HV}$ after 5 days. According to the obtained hardness curves, it was shown that the alloys with the highest content of $\mathrm{Sn}(4 \%$ and $6 \%$ ) were harder than with the content of Al-2\% Sn (the addition of tin actually increases aluminum hardness, so, it becomes more resistant to mechanical shocks). These curves show that, as tin concentration increased, the aging process seemed to be more delayed. Also, the highest tin content $(6 \%)$ resulted in a slight increase in the hardness, which was probably due to the solid solution of Al-Sn.

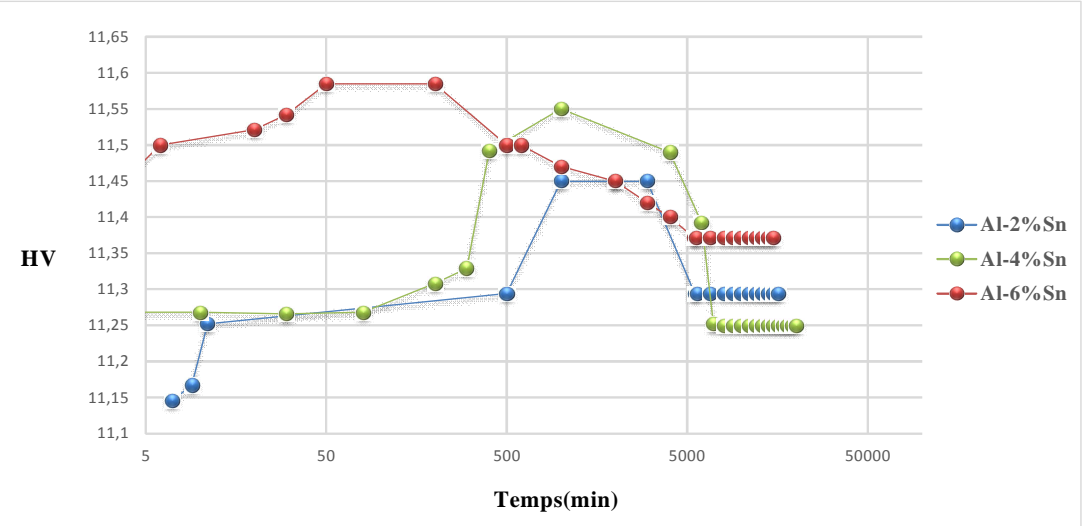

Figure 3. Hardness evolution as a function of time, at room temperature, of Al-Sn cast alloys immersed in water.

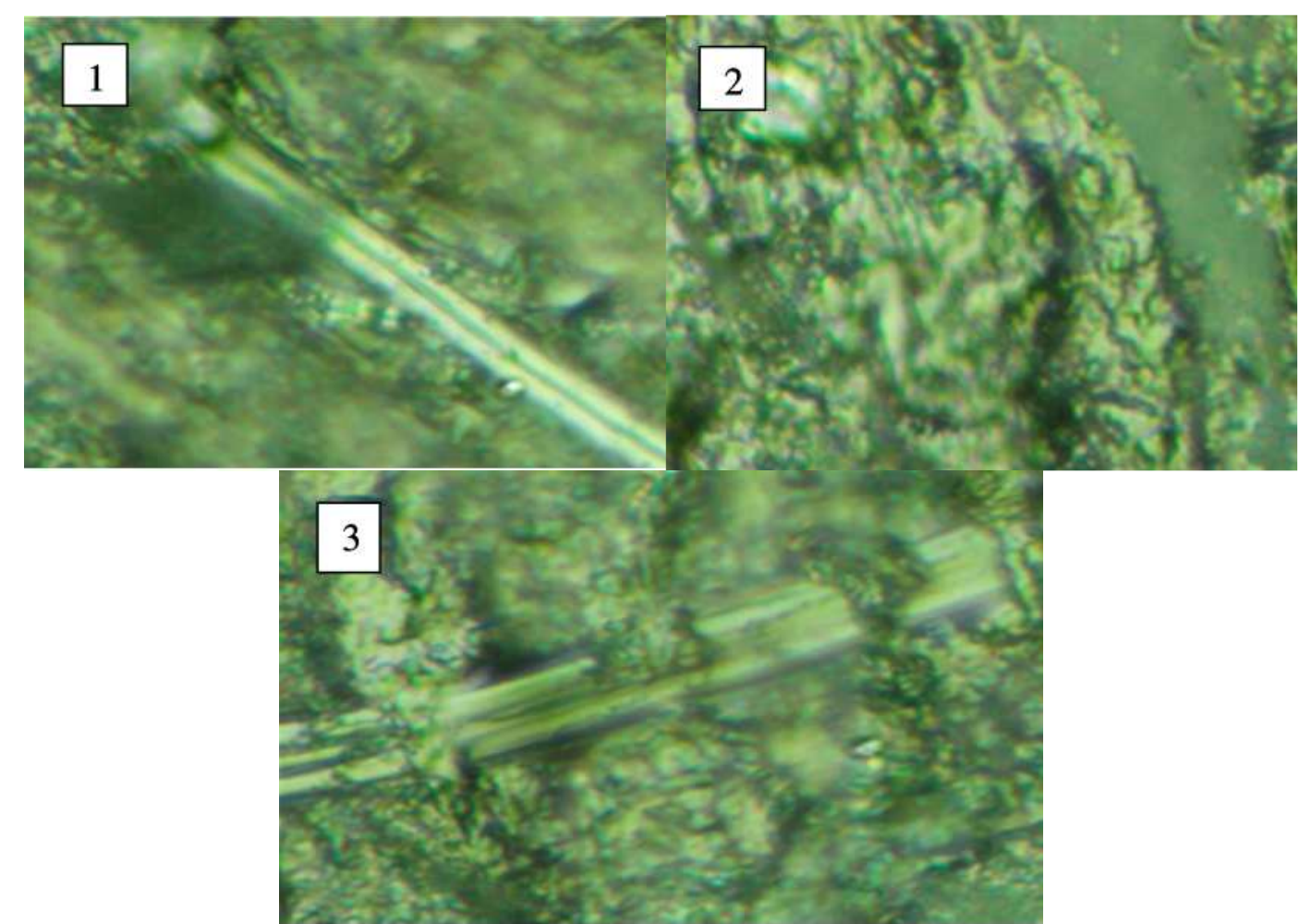

Figure 4. Discontinuous precipitation $\mathrm{Al}-2 \% \mathrm{Sn}(1), \mathrm{Al}-4 \% \mathrm{Sn}(2)$ and $\mathrm{Al}-6 \% \mathrm{Sn}(3)$ at $20^{\circ} \mathrm{C}$, after 20 days of aging.

\section{Optical microscopy}

Fig. 4 shows the visualization by optical microscopy of the precipitates aligned in 
the discontinuous precipitation characterizing over aging. The analysis carried out in the regions affected by over aging shows that the precipitates are fully trained of Sn. However, the analyses of the interlamellar areas are much depleted of tin, and its concentration remains the same throughout the matrix.

\section{Electrochemical techniques}

\section{Electrochemical impedance spectroscopy}

The Nyquist plots shown in Fig. 5 are in the form of a single half-circle; this indicates that the charge transfer was the principal reaction mechanism at the interface of Al-Sn alloys.

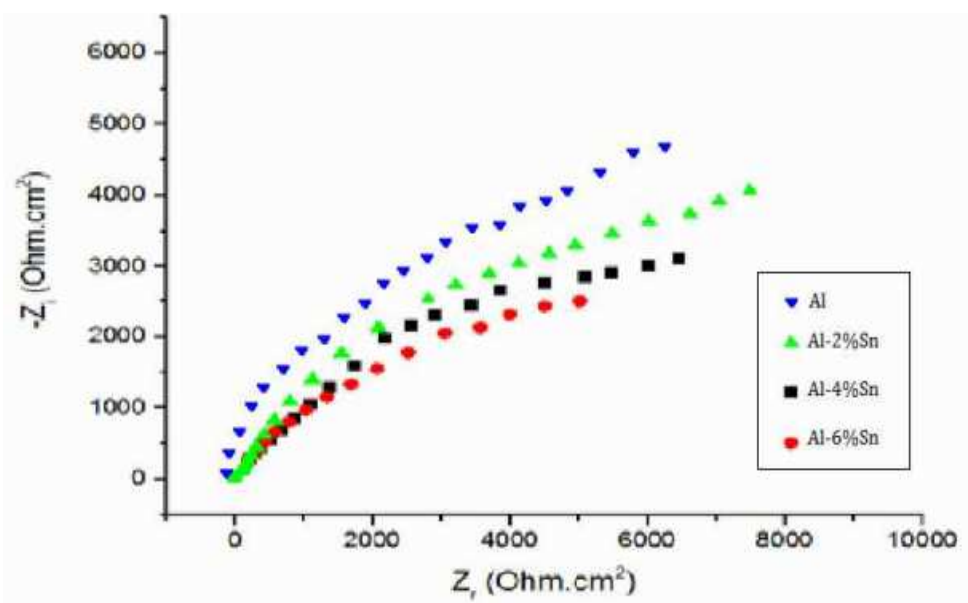

Figure 5. Nyquist plots of Al-Sn alloys with different concentrations of tin in $3 \% \mathrm{NaCl}$.

Table 2. Dielectric parameters characterizing the impedance diagrams of the effect of $\mathrm{Sn}$ addition on the corrosion of $\mathrm{Al}$ in $3 \% \mathrm{NaCl}$, at $25^{\circ} \mathrm{C}$.

\begin{tabular}{|c|c|c|}
\hline Alloy & $\underset{(\text { ohm.cm }}{\text { Rt }}$ & $\begin{array}{c}\mathbf{C}_{\mathrm{dl}} \\
\left(\boldsymbol{\mu} \mathbf{F} / \mathbf{c m}^{2}\right)\end{array}$ \\
\hline Pure Al & 35.52 & 19.76 \\
\hline $\mathrm{Al}-2 \% \mathrm{Sn}$ & 32.24 & 24.68 \\
\hline $\mathrm{Al}-4 \% \mathrm{Sn}$ & 28.81 & 63.11 \\
\hline $\mathrm{Al}-6 \% \mathrm{Sn}$ & 11.45 & 104.93 \\
\hline
\end{tabular}

The parameters represented in Table 2 show that the increase in Sn content led to a decrease in Rt (32.24 ohm.cm ${ }^{2}$ for Al-2\%Sn to $11.45 \mathrm{ohm} . \mathrm{cm}^{2}$ for Al-6\% $\mathrm{Sn}$ ) and an increase in $\mathrm{C}_{\mathrm{dl}}\left(24.68 \mu \mathrm{F} / \mathrm{cm}^{2}\right.$ for Al-2\%Sn to $104.93 \mu \mathrm{F} / \mathrm{cm}^{2}$ for Al$6 \% \mathrm{Sn}$ ). This means that the resistance of the layer that covers aluminum is higher than in the case of pure aluminum, which is more fragile, and the capacity of the double layer of the metal increases with the increase in Sn content.

It can be easily noted that, with the increase in the tin content, the diameter of the half-circles decreased, meaning that the addition of $\mathrm{Sn}$ led to the $\mathrm{Al}$ electrochemical activation. This indicates that the $\mathrm{Al}_{2} \mathrm{O}_{3}$ oxide layer, which was spontaneously formed onto the aluminum surface in contact with air, degraded after $\mathrm{Sn}$ addition. Tin infiltrates into the layer of $\mathrm{Al}_{2} \mathrm{O}_{3}$ and modifies its crystalline structure, leading to its degradation and to aluminum reactivation, which makes Al electro-chemically active and able to be used as an anode for cathodic protection systems. 


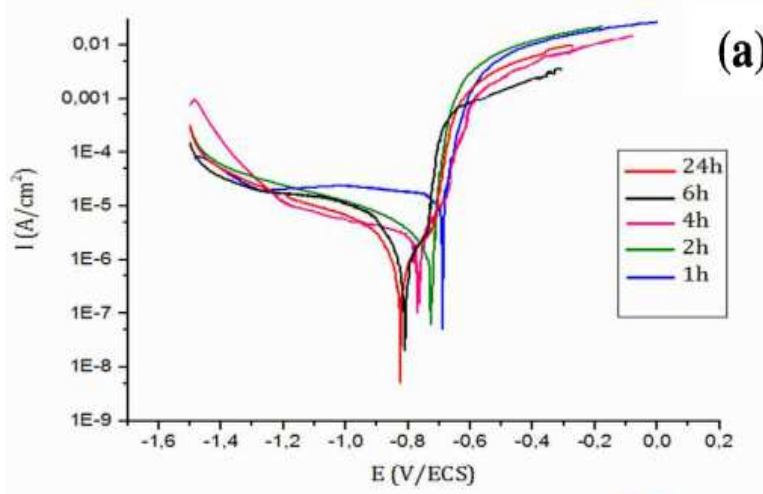

(a)
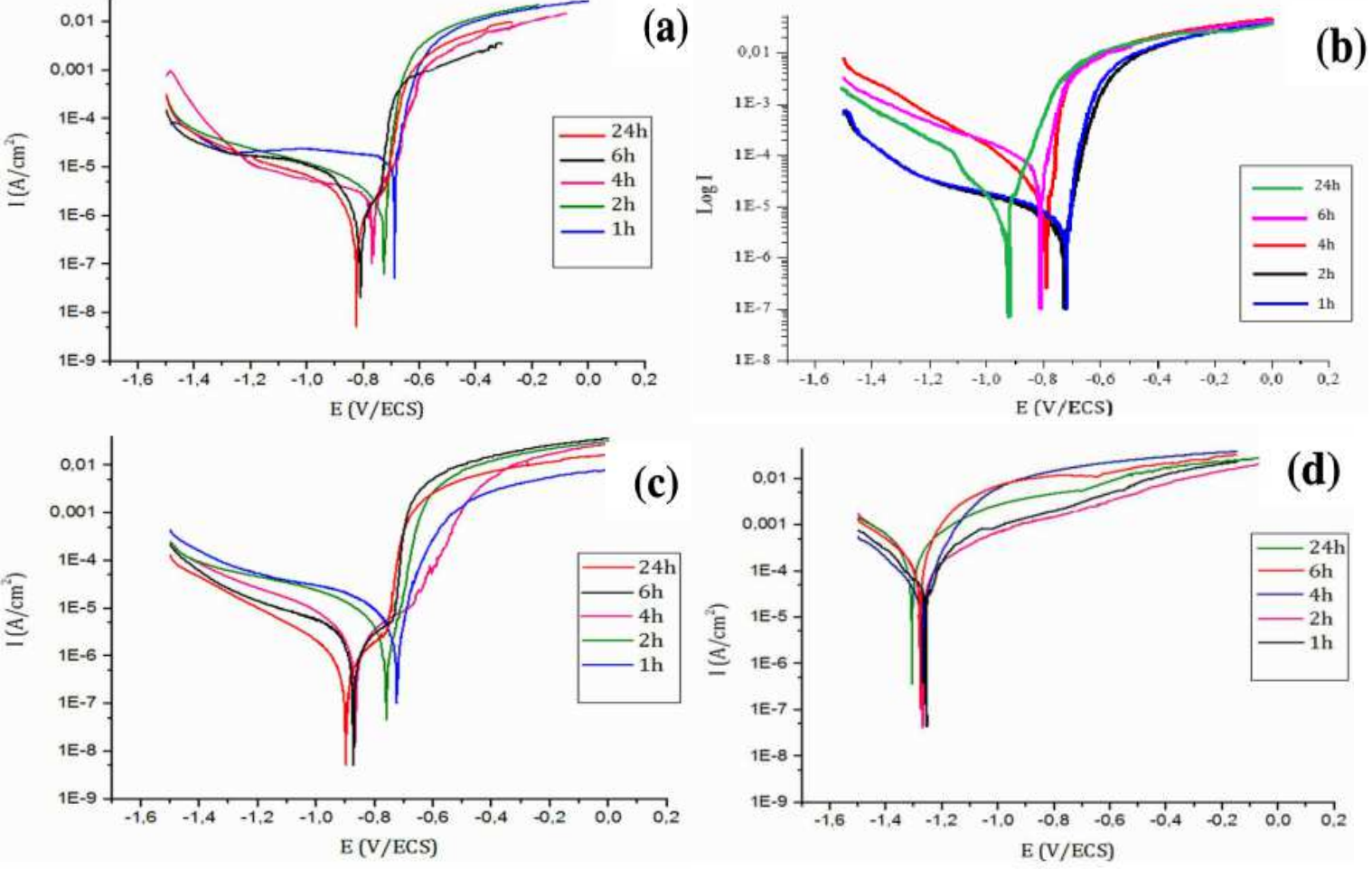

Figure 6. Polarization curves of immersion time effect on pure $\mathrm{Al}$ (a), Al-2\% Sn (b), Al$4 \% \mathrm{Sn}(\mathbf{c})$ and $\mathrm{Al}-6 \% \mathrm{Sn}(\mathbf{d})$, in $3 \% \mathrm{NaCl}$.

Table 3. Polarization I-E curves parameters of pure $\mathrm{Al}$ and of $\mathrm{Al}-2 \% \mathrm{Sn}, \mathrm{Al}-4 \% \mathrm{Sn}$ and Al-6\% Sn alloys in 3\% NaCl.

\begin{tabular}{|c|c|c|c|c|c|c|}
\hline Alloy & $\begin{array}{c}\text { Immersion } \\
\text { time }\end{array}$ & $\begin{array}{c}\text { Ecorr }_{(\mathrm{mV} / \mathrm{ECS})} \\
\text { (m) }\end{array}$ & $\begin{array}{c}\mathbf{I}_{\text {corr }} \\
\left(\mu \mathrm{A} / \mathbf{c m}^{2}\right)\end{array}$ & $\begin{array}{c}\mathbf{R}_{\mathbf{p}} \\
\left(\mu \mathrm{A} / \mathbf{c m}^{2}\right)\end{array}$ & $\boldsymbol{\beta}_{\mathrm{a}}$ & $\boldsymbol{\beta}_{\mathrm{c}}$ \\
\hline \multirow{5}{*}{ Pure Al } & $1 \mathrm{~h}$ & -701 & 0.61 & 7.8 .10 & -109 & 94 \\
\hline & $2 \mathrm{~h}$ & -728 & 0.80 & 5.4 .10 & -115 & 78 \\
\hline & $4 \mathrm{~h}$ & -758 & 1.04 & 3.2 .10 & -102 & 55 \\
\hline & $6 \mathrm{~h}$ & -768 & 1.45 & 2.9.10 & -104 & 32 \\
\hline & $24 \mathrm{~h}$ & -812 & 1.70 & 2.1 .10 & -107 & 99 \\
\hline \multirow{5}{*}{$\mathrm{Al}-2 \% \mathrm{Sn}$} & $1 \mathrm{~h}$ & -710 & 1.87 & 5.2 .10 & -120 & 41 \\
\hline & $2 \mathrm{~h}$ & -723 & 2.03 & 6.0 .10 & -103 & 39 \\
\hline & $4 \mathrm{~h}$ & -793 & 2.79 & 4.7.10 & -110 & 52 \\
\hline & $6 \mathrm{~h}$ & -801 & 3.51 & 3.1 .10 & -98 & 48 \\
\hline & $24 \mathrm{~h}$ & -854 & 8.53 & 2.5 .10 & 102 & 60 \\
\hline \multirow{5}{*}{$\mathrm{Al}-4 \% \mathrm{Sn}$} & $1 \mathrm{~h}$ & -711 & 2.11 & 5.4 .10 & -135 & 33 \\
\hline & $2 \mathrm{~h}$ & -770 & 3.08 & 8.3 .10 & -108 & 40 \\
\hline & $4 \mathrm{~h}$ & -877 & 3.12 & 4.5.10 & -101 & 49 \\
\hline & $6 \mathrm{~h}$ & -875 & 7.55 & 2.1 .10 & -99 & 66 \\
\hline & $24 \mathrm{~h}$ & -901 & 9.22 & 1.2 .10 & -108 & 76 \\
\hline \multirow{5}{*}{ Al-6\% Sn } & $1 \mathrm{~h}$ & -1225 & 13.08 & 7.26 .10 & -160 & 70 \\
\hline & $2 \mathrm{~h}$ & -1280 & 22.67 & 5.33 .10 & -120 & 35 \\
\hline & $4 \mathrm{~h}$ & -1272 & 45.44 & 4.22 .10 & -132 & 40 \\
\hline & $6 \mathrm{~h}$ & -1272 & 98.12 & 3.12 .10 & -117 & 44 \\
\hline & $24 \mathrm{~h}$ & -1310 & 127.20 & 1.16 .10 & -122 & 88 \\
\hline
\end{tabular}




\section{Potentiodynamic polarization}

Influence of immersion time

The anodic and cathodic polarization diagrams of the Al-Sn alloys (with different contents of $\mathrm{Sn}$ ) in $3 \% \mathrm{NaCl}$ are represented in Fig. 6.

The intersection point of the Tafel lines gives the corrosion current density ( $\left.\mathrm{I}_{\text {corr }}\right)$. The obtained polarization parameters $\left(\mathrm{I}_{\mathrm{corr}}, \mathrm{E}_{\mathrm{corr}}, \beta_{\mathrm{a}}\right.$ and $\left.\beta_{\mathrm{c}}\right)$ are represented in Table 3.

After analyzing the polarization curves represented in Fig. 6, as well as the polarization parameters in Table 3, we can clearly see that the immersion time acts in a similar way for all the alloys; the more the electrode is immersed in $3 \%$ $\mathrm{NaCl}$, the more the corrosion potential $\left(\mathrm{E}_{\text {corr }}\right)$ is shifted to the anodic potentials (from $-701 \mathrm{mV} / \mathrm{ECS}$ to $-812 \mathrm{mV} / \mathrm{ECS}$, for Al-2\%Sn, as example) and the more the corrosion current density ( $\mathrm{I}_{\text {corr }}$ ) increases (up to $127.20 \mu \mathrm{A} / \mathrm{cm}^{2}$ for Al-6\%Sn), meaning that the immersion time acts on the alloys by increasing their corrosion. Also, the addition of tin moves the corrosion potential towards more electronegative potentials (from $-701 \mathrm{mV} / \mathrm{ECS}$ for pure Al up to $-1225 \mathrm{mV} / \mathrm{ECS}$ for Al-6\%Sn). Aditionally, it increases the corrosion current density (from 0.61 $\mu \mathrm{A} / \mathrm{cm}^{2}$ for pure $\mathrm{Al}$ up to $13.08 \mu \mathrm{A} / \mathrm{cm}^{2}$ for $\left.\mathrm{Al}-6 \% \mathrm{Sn}\right)$, indicating that the addition of tin leads to electrochemically active aluminum. These results are in very good agreement with those of the electrochemical impedance spectroscopy.

\section{Conclusions}

In this work we have tested different alloys based on aluminum (Al-2\%Sn, Al$4 \% \mathrm{Sn}$ and $\mathrm{Al}-6 \% \mathrm{Sn}$ ) in a solution of $3 \% \mathrm{NaCl}$, so that they could be used as anodes for cathodic protection. The confrontation of experimental results was obtained with the used electrochemical methods, namely, potentiodynamic polarization and electrochemical impedance spectroscopy, which have allowed us to identify the main phenomena governing the reaction mechanism at the electrode/electrolyte interface.

The studies made on the Al-Sn alloys show that the addition of Sn to aluminum has led to more active alloys. This activity is indicated by a shift of the corrosion potential towards more negative values, and also to a reduced passivity of aluminum.

The immersion time of the alloys and the addition of tin favors the reaction between $\mathrm{Al}$ and $\mathrm{NaCl}$, and increases, therefore, metal corrosion.

The addition of tin to aluminum has given, not only a positive effect on the activation of the aluminum, but also on its crystal structure which has become much more hard and resistant to mechanical shocks.

\section{References}

1. Reading JT, Newport JJ. Mater Protect. 1966; 5:15.

2. Perrault GG. J. Electrochem.Soc. 1979; 126:199.

3. Kabanov BN, Astakhovand II, Kiseleva JG. Electrochim Acta. 1979; 24:167.

4. Parsons R. Handbook of Electrochemical Constants. London: Butterworths; 
1959.

5. Richardson JA, Wood GC. Corrosion Sci. 1970; 10: 313.

6. Davis JA, Staklis AA, Watts AA. Into Env Sci. $17^{\text {th }}$ Ann Tech Meet LA, $1971 ; 177$.

7. Brown BF, Fujii CT, Dahlberg EP. J Electrochem Soc. 1969;166: 218.

8. Kitamura K, Sato E. Keikinzuku. 1978; 29:563.

9. Kurov OV, Melekov RL. Zasch Metal. 1979;15:314.

10. Rosenfeld IL, Marshakov IK. Corrosion. 1964;20:115t.

11. De Mecheli SM. Corrosion Sci. 1978;18:605.

12. Edeleanu E, Evans UR. Trans Faraday Soc. 1951;47:1121.

13. Marek M, Kinker JR, Hochman RF. $6^{\text {th }}$ Int Congress Metallic Corrosion. Syneny; 1975.

14. Gimenez P, Rameau JJ, Reboul MC. Corrosion. 1981;37:673.

15. Dexter SC. Corrosion. 1980;36:423-432.

16. Hilger JP, Boulahrouf A. Mater Charact. 1990;24:159. 